\title{
Apreciação de contas de governos: uma análise nos municípios de Santa Catarina
}

Como auxiliares no papel de fiscalização, por meio do Controle Externo, os Tribunais de Contas exercem análise técnica das prestações de contas dos prefeitos municipais antes do julgamento pelo Poder Legislativo. No entanto, o Pleno dessas Cortes é composto por membros indicados por representantes políticos, o que pode permitir existência de influência de outros interesses, como políticos, na apreciação das contas de governo. Essa pesquisa tem como objetivo investigar se existe diferença na apreciação das contas dos governos municipais do estado de Santa Catarina, em decorrência da natureza do Relator. Para tanto, foram categorizados os relatores entre indicados politicamente ou não, além de verificado o alinhamento político com os prefeitos. Foram analisadas as prestações de contas de 100 municípios catarinenses, entre os anos de 2012 a 2018. Os resultados indicam que existe influência política na apreciação das contas pelo TCE/SC, tanto por meio da verificação do reflexo do alinhamento político entre prefeito e relator, quanto pela análise da natureza do cargo do relator - se titular, indicado politicamente ou auditor substituto concursado. De forma geral, relatores conselheiros tendem a aprovar mais contas do que relatores auditores. Quando alinhados politicamente aos prefeitos, esse efeito é ainda maior. Além disso, somente conselheiros levantam voto divergente para aprovar contas opinadas pela rejeição. Os resultados corroboram com pesquisas anteriores sobre a existência de influência política no exercício de controle externo.

Palavras-chave: Influência política; Tribunais de Contas; Prestação de contas.

\section{Assessment of government accounts: an analysis in the city of Santa Catarina}

\begin{abstract}
As assistants in the supervisory role, through External Control, the Courts of Accounts carry out technical analysis of the accountability of municipal mayors before judgment by the Legislative Branch. However, the Plenum of these Cortes is composed of members appointed by political representatives, which may allow for the influence of other interests, such as politicians, in the assessment of government accounts. This research aims to investigate whether there is a difference in the appreciation of the accounts of municipal governments in the state of Santa Catarina, due to the nature of the Rapporteur. To this end, the rapporteurs were categorized as politically indicated or not, in addition to checking the political alignment with the mayors. The account payments of 100 municipalities in Santa Catarina were analyzed between the years 2012 to 2018. The results indicate that there is a political influence on the appreciation of the accounts by the TCE/SC, both through the verification of the reflection of the political alignment between mayor and rapporteur, as for the analysis of the nature of the position of the rapporteur - whether incumbent, politically appointed or substituted auditor with a competitive exam. In general, advisory rapporteurs tend to approve more accounts than auditors. When politically aligned with mayors, this effect is even greater. In addition, only board members cast a dissenting vote to approve accounts opposed by the rejection. The results corroborate with previous research on the existence of political influence in the exercise of external control.
\end{abstract}

Keywords: Political influence; Courts of Accounts; Accountability.

Topic: Contabilidade Pública

Reviewed anonymously in the process of blind peer.

Camila Cristine da Silva Alves (iD)

Universidade Federal de Santa Catarina, Brasil

http://lattes.cnpq.br/2024126785949137

http://orcid.org/0000-0002-9604-9364

camilacsalves@gmail.com

Alex Mussoi Ribeiro (iD

Universidade Federal de Santa Catarina, Brasil

http://lattes.cnpq.br/3019901891300844

http://orcid.org/0000-0003-3389-9713

alex.mussoi@ufsc.br
Received: $10 / 10 / 2020$

Approved: 21/12/2020

\section{Referencing this:}

ALVES, C. C. S.; RIBEIRO, A. M.. Apreciação de contas de governos: uma análise nos municípios de Santa Catarina. Revista Brasileira de Administração Científica, v.11, n.4, p.242-258, 2020. DOI: http://doi.org/10.6008/CBPC2179-684X.2020.004.0019 


\section{INTRODUÇÃO}

A atuação dos gestores públicos, constitucionalmente, é objeto de fiscalização pelo Poder Legislativo com auxílio dos Tribunais de Contas (BRASIL, 1988). No caso das contas de governos municipais, os Tribunais de Contas, em sessão plenária, apreciam e emitem parecer prévio para posterior julgamento pela Câmara de Vereadores. Ocorre que, se por um lado os administradores públicos (chefes do poder executivo) e membros das casas legislativas (vereadores e deputados) são eleitos direta e democraticamente pelos cidadãos (BRASIL, 1988), por outro, a população pode ficar refém da escolha dos conselheiros dos Tribunais de Contas, indicados, no caso dos estados, pelo governador e pela Assembleia Legislativa. Esses conselheiros indicados compõem o pleno da Corte de Contas e emitem opinião sobre os processos de prestações de contas, antes seguirem para julgamento no Legislativo.

Um alto percentual de políticos ocupando cadeiras nos Tribunais de Contas pode levar esses conselheiros a terem uma visão mais simpática ao seu grupo político, comprometendo o caráter técnico da função. Dessa forma, o desenho institucional é vulnerável à captura política (OLIVEIRA, 2018). No mesmo viés, os grupos de interesse políticos podem se sentir mais encorajados a atuarem junto aos Conselheiros, de forma a evitar a rejeição de suas contas de governo, especialmente após a promulgação da Lei da Ficha Limpa (Lei Complementar no 135 - BRASIL, 2020), sob risco de inelegibilidade por oito anos.

Apesar do controle externo objetivar a comprovação da probidade da Administração, "no Brasil, em que o Tribunal de Contas (TC), em todos os níveis, não atua com plena independência, registra-se insatisfação a respeito de seu desempenho, notando-se descrédito da população em geral e queixas de seus próprios integrantes" (MEDAUAR, 1992).

O sistema jurídico brasileiro comporta diversas espécies de responsabilização aos agentes públicos pelos atos praticados. Para tanto, é necessário dar satisfação sobre estes atos. 0 instrumento pelo qual o controle externo pode ser exercido sobre a atividade administrativa do Estado é a prestação de contas (PC).

A prestação de contas anual dos chefes do Poder Executivo dos municípios é enviada ao Tribunal de Contas a que pertencem para apreciação e emissão de parecer prévio com opinião pela aprovação - com ou sem ressalvas - ou rejeição das contas. Este parecer prévio é encaminhado ao Poder Legislativo para julgamento, com emissão do parecer final e conclusivo das contas, e pode deixar de prevalecer por decisão de dois terços dos membros da Casa Legislativa.

A atuação dos Tribunais de Contas, nesse processo, deve ser isonômica e imparcial em qualquer circunstância, apegando-se apenas à análise da legalidade, legitimidade e economicidade dos atos de gestão do administrador público de forma a contribuir tecnicamente no julgamento posterior. No âmbito do Legislativo, apesar do caráter político do controle, a fiscalização com o consequente julgamento das contas deve se dar de forma a honrar o papel ocupado pelos representantes eleitos democraticamente para a defesa do interesse público, levando em consideração a avaliação técnica da prestação de contas.

Estudo publicado pela Organização Não-Governamental - ONG Transparência Brasil revela que os Tribunais de Contas brasileiros são majoritariamente compostos por ex-políticos de carreira. Isso é possível 
em decorrência do desenho institucional estabelecido constitucionalmente, que coloca as cadeiras de Conselheiros como cargos de indicação por representantes políticos. Assim, pode-se esperar que exista uma influência político-partidária nesta fase técnica de análise da prestação de contas, em especial, quando submetida ao Pleno do Tribunal de Contas. A predominância de políticos no preenchimento das vagas do pleno permite inferir a facilidade de acesso do meio político-partidário, o que pode levar a um exame influenciado por circunstâncias de ordem política, em detrimento dos aspectos técnicos.

Em estudo recente, Martins et al. (2020) investigaram a influência política no julgamento das contas públicas municipais no estado de Pernambuco. Os resultados encontrados apontam que o número de vereadores alinhados ao partido do prefeito influencia na aprovação das contas do prefeito julgado, mesmo tendo a Corte de Contas opinado pela rejeição. Na mesma linha, Almeida-Santos et al. (2018) buscaram identificar a probabilidade de sucesso ou fracasso na prestação de contas dos municípios catarinenses e incluíram, entre outros, fatores político-ideológicos na análise. Os autores concluíram que, quando existe aliança partidária do prefeito com o executivo estadual, a probabilidade de sucesso na aprovação das contas é aumentada.

Os achados dessas pesquisas e a condição de composição dos Tribunais de Contas - TCs sugerem a existência de influência política no processo de análise das prestações de contas municipais, o que reforça a discussão acerca da forma com que o controle externo é exercido no Brasil. Essa pesquisa objetiva analisar a influência de fatores políticos na apreciação das contas dos governos municipais de Santa Catarina. Para tanto, analisou-se o reflexo da convergência político-partidária na apreciação das contas dos gestores públicos municipais pelo Tribunal de Contas do Estado de Santa Catarina e também se existe diferença na apreciação em decorrência da natureza do cargo do relator (se conselheiro indicado politicamente ou auditor substituto de conselheiro) sobre a rejeição ou aprovação das contas públicas municipais.

Como contribuições práticas, essa pesquisa investiga as influências políticas no processo de apreciação de contas, o que contribui para promover mais transparência sobre a forma com que é exercido o controle externo em Santa Catarina e instrumentaliza o controle social não só sobre a atuação de seus representantes, como também de seus órgãos fiscalizadores. Nos dias atuais, a indicação de ministros e conselheiros é ponto de críticas que ensejam inclusive movimentos e iniciativas que propõem alteração no modelo concebido. Dessa forma, essa pesquisa também busca contribuir com uma crítica ao modelo, tentando demonstrar de forma prática as suas fragilidades.

\section{REVISÃO TEÓRICA}

\section{Controle da Função Administrativa do Estado}

No Estado Democrático de Direito, o controle representa um fundamental instrumento para garantir a realização do interesse público (ATALIBA, 1985; CASTRO, 2007; ABRAHAM, 2013). A Administração Pública, como "organização subalterna a serviço da comunidade" (ENTERRÍA, 1985), deve obedecer aos critérios estabelecidos nos princípios e regras constitucionais, os quais trazem na essência de seus conteúdos normas 
a serem seguidas pelos agentes estatais, que devem ter como único objetivo a satisfação do interesse público (CANOTILHO, 1991).

Se a coisa pública é pertencente ao povo, perante o povo todos os seus gestores devem responder (ATALIBA, 1985). Dessa forma, os gestores públicos, no exercício da atividade administrativa da coisa pública, devem prestar contas à sociedade sobre suas ações. Essa responsabilidade acompanha noções de fiscalização, ao passo que os administradores estão sujeitos ao controle administrativo em favor do interesse público (ATALIBA, 1985). O controle da Administração Pública está previsto na Constituição da República Federativa do Brasil de 1988 (BRASIL, 1988), que estabelece o exercício sob dois aspectos: controle interno e controle externo.

\section{Controle externo da Administração Pública e Tribunais de Contas no Brasil}

O controle externo é aquele exercido por órgão estatal estranho àqueles responsáveis pelo ato controlado. É de competência, por exemplo, das ouvidorias, do Ministério Público ou dos Poderes Legislativos, auxiliados pelos Tribunais de Contas. Capobianco (2012) explica, objetivamente, os diversos aspectos de fiscalização mediante controle externo: a fiscalização contábil busca a conformidade dos registros de receita e despesa; a fiscalização financeira compreende primordialmente o controle sobre depósitos bancários, pagamento e recebimento de valores, presentes, pretéritos e mesmo futuros, assim como toda a matéria financeira do ente, com potencial de apresentar qualquer relevância. A fiscalização orçamentária abarca o equilíbrio orçamentário, os registros nas rubricas e ordens expedidas.

No aspecto operacional, a fiscalização incide sobre a execução de atividades administrativas em geral, atinente ao funcionamento da máquina administrativa e o cumprimento dos princípios da celeridade e da eficiência. Por fim, a fiscalização patrimonial, diz respeito aos bens públicos e sua destinação, afetação, uso, conservação, mesmo em almoxarifados de setores públicos ou onde a esfera pública possua ingerência apta a conclamar a fiscalização.

A fiscalização estabelecida tem por objeto três elementos: legalidade, legitimidade e economicidade. Objetivamente, a legalidade está relacionada ao atendimento aos requisitos normativos na gestão da coisa pública, a legitimidade é relacionada com a conveniência e eficiência do gasto e a economicidade se refere ao menor custo possível na realização da despesa (DEPRÁ et al., 2017).

Dessa forma, o controle externo objetiva comprovar a probidade da Administração e a regularidade da guarda e do emprego dos bens, valores e dinheiros públicos, e a fiel execução do orçamento. É, por excelência, um controle político e de legalidade contábil e financeira, o primeiro aspecto a cargo do Legislativo e o segundo, dos Tribunais de Contas (MEIRELLES, 1973).

Siraque (2004) destaca que, essa função fiscalizatória é de extrema importância para a proteção da coisa pública, uma vez que o Legislativo representa, formalmente, a pluralidade ideológica da sociedade e a vontade do povo. Portanto, tem o dever de zelar pelo patrimônio público, em sentido amplo, exercendo a função de controle institucional externo dos responsáveis pela função administrativa do Estado.

Dado que na área estatal não há mecanismos naturais de correção de desvios como "competição" e 
"lucro", que na atividade privada funcionam como potentes instrumentos para reduzir desperdícios, melhorar o desempenho e alocar recursos de forma mais eficiente, a atividade de controle e fiscalização se torna necessária para a garantia do bem comum.

\section{Tribunais de Contas}

Os Tribunais de Contas, antes de tudo, são órgãos de extração constitucional. A primeira Constituição Republicana, de 1891, por anterior inspiração de Rui Barbosa, criou o Tribunal de contas em seu artigo 89:

É instituído um Tribunal de Contas para liquidar as contas da receita e despesa e verificar a sua legalidade, antes de serem prestadas ao Congresso. Os membros deste Tribunal serão nomeados pelo Presidente da República com aprovação do Senado, e somente perderão os seus lugares por sentença.

De lá para cá, as demais constituições brasileiras mantiveram esse órgão de controle externo e ampliaram suas competências, de forma que os tribunais passaram a ser mais do que verificadores da legalidade de despesas.

Apesar de importantes, os Tribunais de Contas não são órgãos cuja eventual inexistência violaria os princípios democrático, republicano e de separação dos poderes. Isso fica claro quando se observa que há países reconhecidamente democráticos e politicamente estáveis, como Canadá, Estados Unidos e Reino Unido, que não dispõem de uma Corte de Contas (ROCHA, 2002; HELLER et al., 2019).

Por outro lado, o mesmo não se pode afirmar sobre a função de controle externo: países que conferem aos seus cidadãos o direito à boa gestão da coisa pública, de forma a prevenir o arbítrio da administração do patrimônio público, possuem órgãos incumbidos da função de controle externo.

Essa função, geralmente compartilhada com o Poder Legislativo, pode ser exercida por órgãos singulares como Controladorias-Gerais e Auditorias-Gerais ou colegiados como os Tribunais de Contas, integrantes ou não da estrutura de algum poder.

Como exemplos de Controladorias-Gerais ou Auditorias-Gerais, Heller et al. (2019) trazem o Office of the Auditor General, no Canadá, o Government Accountability Office, nos Estados Unidos, e o National Audit Office, no Reino Unido. Esses órgãos manifestam-se de forma unipessoal (controlador-geral ou auditorgeral), em contraste com o caráter colegiado das decisões dos Tribunais de Contas.

No Brasil, apesar de o art. 71 da Constituição estabelecer atuação conjunta da Corte de Contas da União e do Congresso Nacional em matéria de controle externo, o TCU não é órgão ou instituição que se acantone na intimidade estrutural do Congresso Nacional. Por outro lado, não opera essa mesma Corte de Contas como órgão meramente auxiliar. Sua atuação jurídica se dá a latere do Congresso, junto dele, mas não do lado de dentro (BRITTO, 2001).

Britto (2001) explica que a ideia de auxílio trazido na Constituição, quando estabelece que o Congresso Nacional exercerá o controle externo "com o auxílio do Tribunal de Contas da União" (art. 71) (BRASIL, 1988), quer dizer que não se pode exercer controle externo sem a participação compulsória das Cortes de Contas, o que não representa superioridade de um perante o outro, mas condição de necessidade.

Os Tribunais de Contas receberam dos legisladores um aparato legal e instrumental que Ihes 
consolida a sua independência pelas amplas atribuições e competências exclusivas elencadas no art. 71 da CRFB/88 e, mais recentemente, pela Lei de Responsabilidade Fiscal - LRF (Lei Complementar 101 - BRASIL, 2000). Essas competências vão desde a aplicação de sanções aos agentes públicos diante de ilegalidades ou irregularidades identificadas nas contas públicas à apreciação das contas anuais do chefe do Poder Executivo, vejamos:

Art. 71. O controle externo, a cargo do Congresso Nacional, será exercido com o auxílio do Tribunal de Contas da União, ao qual compete:

I - apreciar as contas prestadas anualmente pelo Presidente da República, mediante parecer prévio que deverá ser elaborado em sessenta dias a contar de seu recebimento;

II - julgar as contas dos administradores e demais responsáveis por dinheiros, bens e valores públicos da administração direta e indireta, incluídas as fundações e sociedades instituídas e mantidas pelo Poder Público federal, e as contas daqueles que derem causa a perda, extravio ou outra irregularidade de que resulte prejuízo ao erário público;

III - apreciar, para fins de registro, a legalidade dos atos de admissão de pessoal, a qualquer título, na administração direta e indireta, incluídas as fundações instituídas e mantidas pelo Poder Público, excetuadas as nomeações para cargo de provimento em comissão, bem como a das concessões de aposentadorias, reformas e pensões, ressalvadas as melhorias posteriores que não alterem o fundamento legal do ato concessório;

IV - realizar, por iniciativa própria, da Câmara dos Deputados, do Senado Federal, de Comissão técnica ou de inquérito, inspeções e auditorias de natureza contábil, financeira, orçamentária, operacional e patrimonial, nas unidades administrativas dos Poderes Legislativo, Executivo e Judiciário, e demais entidades referidas no inciso II;

V - fiscalizar as contas nacionais das empresas supranacionais de cujo capital social a União participe, de forma direta ou indireta, nos termos do tratado constitutivo;

VI - fiscalizar a aplicação de quaisquer recursos repassados pela União mediante convênio, acordo, ajuste ou outros instrumentos congêneres, a Estado, ao Distrito Federal ou a Município;

VII - prestar as informações solicitadas pelo Congresso Nacional, por qualquer de suas Casas, ou por qualquer das respectivas Comissões, sobre a fiscalização contábil, financeira, orçamentária, operacional e patrimonial e sobre resultados de auditorias e inspeções realizadas;

VIII - aplicar aos responsáveis, em caso de ilegalidade de despesa ou irregularidade de contas, as sanções previstas em lei, que estabelecerá, entre outras cominações, multa proporcional ao dano causado ao erário;

IX - assinar prazo para que o órgão ou entidade adote as providências necessárias ao exato cumprimento da lei, se verificada ilegalidade;

X - sustar, se não atendido, a execução do ato impugnado, comunicando a decisão à Câmara dos Deputados e ao Senado Federal;

$\mathrm{XI}$ - representar ao Poder competente sobre irregularidades ou abusos apurados.

Na análise das contas anuais, o Tribunal de Contas atua como órgão administrativo, limitando-se a analisar as despesas governamentais e sobre elas emitir um parecer técnico, que servirá de subsídio para o efetivo julgamento por parte do Poder Legislativo (AMORIM, 2012). Embora o art. 71 da Constituição Federal (BRASIL, 1988), faça menção ao âmbito federal, o art. 75 estende a mesma disciplina aos Tribunais de Contas dos Estados e do Distrito Federal, dos Municípios e aos Conselhos de Contas dos Municípios, respeitados o princípio federativo e seus desdobramentos. Assim, no caso dos municípios, as contas do Prefeito serão apreciadas pelos Tribunais de Contas dos Municípios ou, na falta destes, pelo Tribunal de Contas do respectivo Estado. 
O Tribunal de Contas da União (TCU) é composto por nove ministros que possuem as mesmas garantias, prerrogativas, vencimentos e impedimentos dos Ministros do Superior Tribunal de Justiça (art. 73, § 3으, CRFB) (BRASIL, 1988). Um terço dos ministros são de indicação do Presidente da República, mediante aprovação do Senado Federal, sendo dois deles escolhidos alternadamente entre auditores e membros do Ministério Público junto ao Tribunal de Contas, indicados em lista tríplice pelo próprio Tribunal, segundo os critérios de antiguidade e merecimento. Os outros dois terços dos ministros são indicados pelo Congresso Nacional (art. 73, § 2으, incisos I e II, CRFB) (BRASIL, 1988).

Os requisitos necessários para concorrer à uma vaga de Ministro do Tribunal de Contas da União, estão dispostos no $§ 1$ 을 do art. 73 da CRFB de 1988:

$\S 1$ 응 Os Ministros do Tribunal de Contas da União serão nomeados dentre brasileiros que satisfaçam os seguintes requisitos:

I - mais de trinta e cinco e menos de sessenta e cinco anos de idade;

II - idoneidade moral e reputação ilibada;

III - notórios conhecimentos jurídicos, contábeis, econômicos e financeiros ou de administração pública;

IV - mais de dez anos de exercício de função ou de efetiva atividade profissional que exija os conhecimentos mencionados no inciso anterior. (BRASIL, 1988)

Na esfera dos Estados, a estrutura dos Tribunais de Contas atende aos parâmetros e critérios estabelecidos pelas respectivas Constituições Estaduais, respeitadas as disposições da Constituição Federal de 1988 (art. 75 e seu parágrafo único), a qual dispõe que os Tribunais de Contas dos Estados serão integrados por sete conselheiros. Nessas unidades, em decorrência da quantidade de membros, a distribuição em terços encontra alguma dificuldade. No entanto, é pacífica a jurisprudência do Supremo Tribunal Federal, no sentido de que, nos Tribunais de Contas, compostos por sete membros, quatro devem ser escolhidos pela Assembleia Legislativa e três pelo chefe do Poder Executivo Estadual, cabendo a este indicar um dentre auditores e outro dentre membros do Ministério Público, e um terceiro a sua livre escolha (Súmula 653 - BRASIL, 2013).

O formato de composição dos Tribunais de Contas, por indicação política, pode se refletir no perfil dos conselheiros nomeados. Estudo publicado pela ONG Transparência Brasil, que se dedicou a explorar o perfil dos conselheiros dos Tribunais de Contas do Brasil, aponta que a maioria dos conselheiros chegam às cortes após exercer mandatos políticos ou cargos em governos, ou seja, possuem uma vida política pregressa.

A composição dos Tribunais de Contas é um dos pontos de maior polêmica no âmbito do Controle Externo. Propostas de Emendas à Constituição (PECs) que eliminam as indicações políticas para os Tribunais de Contas já foram elaboradas e vêm sendo debatidas.

A Proposta de Emenda à Constituição (PEC) no. 2 de 2018, do Senado Federal tem o intuito de modificar a forma de composição do Tribunal de Contas da União, dos Tribunais de Contas dos Estados e do Distrito Federal e dos Tribunais e Conselhos de Contas dos Municípios. A intenção é eliminar o critério da indicação política para impor à Cortes de Contas uma composição majoritária de selecionados em concursos públicos de provas e títulos (BRASIL, 2018).

Nessa mesma linha, a PEC 329/13, da Câmara dos Deputados, prevê a realização de concurso público 
de provas e títulos para as carreiras dos órgãos de contas, além de determinar a fiscalização pelo Conselho Nacional de Justiça (CNJ) e pelo Conselho Nacional do Ministério Público (CNMP), entre outras medidas.

Ambas as propostas nascem da necessidade de profissionalização do controle de contas públicas pelos Tribunais de Contas e órgãos correlatos, eliminando, pura e simplesmente, as indicações políticas. Entre as justificativas apresentadas, argumenta-se que aproximadamente $25 \%$ dos membros dos TCEs não possuem formação adequada para o exercício da função. No entanto, o problema mais grave do modelo de controle externo exercido no Brasil, segundo consta nas PECs, é o estreito vinculo mantido e cultivado entre muitos dos membros nomeados para as Cortes de Contas e as forças políticas responsáveis pelas suas nomeações. Nesse sentido, as propostas convergem sobre a necessidade de afastar dessas Cortes a influência político-partidária (PEC 329/13 e PEC 2/2018).

\section{Prestação de Contas dos Prefeitos}

Especificamente no contexto legal, o parágrafo único do artigo 70 da Constituição Federal de 1988 dispõe que prestará contas "qualquer pessoa física ou jurídica, pública ou privada, que utilize, arrecade, guarde, gerencie ou administre dinheiros, bens e valores públicos ou pelos quais a União responda, ou que, em nome desta, assuma obrigações de natureza pecuniária". Assim sendo, qualquer pessoa que use ou esteja responsável por bens ou recursos públicos, em qualquer circunstância, tem o dever de prestar contas de sua gestão, demonstrando o atendimento à finalidade pública.

O art. 48 da Lei de Responsabilidade Fiscal (Lei Complementar n. 101 - BRASIL, 2000) define como instrumentos de transparência e da gestão fiscal - aos quais deverá ser dada ampla divulgação - os planos, orçamentos e leis de diretrizes orçamentárias; as prestações de contas e o respectivo parecer prévio; o Relatório Resumido da Execução Orçamentária e o Relatório de Gestão Fiscal; e as versões simplificadas desses documentos.

De forma complementar, seu artigo 58 estabelece que prestação de contas evidenciará o desempenho da arrecadação das receitas, evidenciando as providências adotadas no âmbito da fiscalização das receitas e combate à sonegação, as ações de recuperação de créditos nas instâncias administrativa e judicial, bem como as demais medidas para incremento das receitas tributárias e de contribuições. Dessa forma, a Lei parte do pressuposto de que o administrador de recursos públicos age com responsabilidade, de forma a preservar o patrimônio com eficiência, seja evitando perdas desnecessárias ou não legítimas, seja tomando medidas para melhorias na arrecadação de receitas.

Segundo a visão de Amorim (2012), a partir da leitura do art. 71 da Constituição Federal, é possível constatar a existência de dois regimes jurídicos de contas públicas: a) regime de contas de governo: relativo à gestão política do Chefe do Poder Executivo, cujo julgamento político dar-se-á pelo Poder Legislativo, mediante auxílio do Tribunal de Contas, que emitirá parecer prévio (art. 71, I, c/c art. 49, IX) (BRASIL, 1988); b) regime de contas de gestão: são prestadas ou tomadas por administradores de recursos públicos, cujo julgamento, de ordem técnica, é realizado definitivamente pelo Tribunal de Contas respectivo (art. 71, II) (BRASIL, 1988). Neste caso, o julgamento, materializado em acórdão, terá eficácia de título executivo (art. 
71, § 3) (BRASIL, 1988), quando imputar débito (reparação de dano patrimonial) ou aplicar multa (punição).

Por conseguinte, no ordenamento jurídico pátrio existem três espécies de prestação de contas: a Prestação de Contas de Governo, a Prestação de Contas de Gestão e a Prestação de Contas Especial (Aguiar, 2003). Essa pesquisa concentra-se na análise das prestações de contas de governo. A apreciação desses processos no Tribunal de Contas segue o seguinte fluxo:

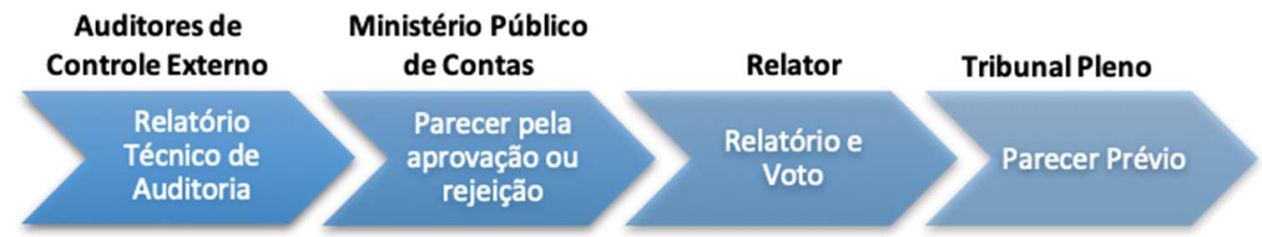

Figura 1: Fluxo de análise das prestações de contas municipais pelo TCE/SC.

Assim, o corpo técnico do Tribunal de Contas elabora um Relatório que contém informações sobre a observância das normas constitucionais, legais e regulamentares na execução orçamentária, cumprimento dos programas previstos nas peças orçamentárias, resultados de inspeções e auditorias no exercício, entre outras informações que podem ser requeridas pelo Relator. Esse relatório é encaminhado ao Ministério Público de Contas (MPC), que emite parecer com opinião pela rejeição ou aprovação das contas.

O processo então é remetido ao Relator, escolhido por sorteio para apreciar as contas. O relator pode ser um conselheiro titular, investido no cargo por indicação política, ou um auditor substituto de conselheiro, que assume a atribuição do conselheiro na sua ausência. Da análise do relator é apresentada ao Tribunal Pleno por meio de Relatório e Projeto de Parecer Prévio. Pelo voto da maioria dos conselheiros do Pleno, o TCE/SC expede o Parecer Prévio com recomendação pela aprovação, aprovação com ressalvas ou rejeição das contas do prefeito analisado (Resolução N. TC 06/2002).

O parecer prévio emitido pelo TCE consiste em apreciação geral e fundamentada da gestão orçamentária, patrimonial e financeira havida no exercício, devendo demonstrar se o Balanço Geral do Município representa adequadamente a posição financeira, orçamentária e patrimonial do Município em 31 de dezembro, bem como se as operações estão de acordo com os princípios fundamentais de contabilidade aplicados à administração pública municipal (Lei Complementar no 202 - SANTA CATARINA, 2000). Recomenda a aprovação ou a rejeição das contas. É um parecer opinativo, no qual para fins de julgamento pela Câmara de Vereadores só deixará de prevalecer, no caso dos municípios, por decisão de dois terços dos membros da Casa Legislativa (§ 2o, do art. 31) (BRASIL, 1988). A rejeição das contas municipais pela Câmara de Vereadores, segundo a Lei da Ficha Limpa (Lei Complementar no 135 - BRASIL, 2010), é um dos pressupostos para ensejar inelegibilidade do agente político responsável para as eleições que se realizarem nos 8 (oito) anos seguintes à decisão.

\section{METODOLOGIA}

A pesquisa é caracterizada, quanto aos objetivos, como descritiva. De acordo com Andrade (2010), a pesquisa descritiva é aquela em que os fatos são observados, registrados, analisados, classificados e 
interpretados, sem interferência do pesquisador. Quanto à obtenção dos dados, é documental e quanto à abordagem do problema, qualitativa.

Para a realização dessa pesquisa, foram consultadas as prestações de contas dos gestores públicos dos 100 municípios mais populosos do estado de Santa Catarina, em um universo temporal que envolve os anos de 2012 a 2018. A amostra resultou em 699 observações. Os dados utilizados na pesquisa são secundários, coletados de forma manual no website do Tribunal de Contas do Estado de Santa Catarina e do Tribunal Regional Eleitoral de Santa Catarina. A análise se baseia na opinião do relator pela aprovação ou rejeição da prestação de contas. O objetivo da pesquisa é investigar se existe diferença na apreciação das contas de governos municipais do estado de Santa Catarina, em decorrência na natureza do relator.

Para tanto, além de categorizar os relatores como indicados politicamente ou não, realiza-se a análise sobre a influência do alinhamento político-partidário entre os envolvidos no processo de apreciação das contas. Dessa forma, entre os relatores Conselheiros, é considerada a origem política de cada um. Para os que exerciam cargo político na época em que foram indicados à vaga no Tribunal, Ihes é atribuído o partido político ao qual pertenciam no momento da indicação. Aos que não ocupavam cargo político, atribui-se o partido político do governador que os nomeou. Como os Auditores Substitutos de Conselheiro ingressaram na carreira por meio de concurso público, não lhes é atribuído nenhum partido político.

A análise do alinhamento político é realizada pela comparação do partido político atribuído a cada um dos relatores com o partido político ao qual cada prefeito municipal cujas contas foram apreciadas se elegeu. De forma complementar, foram analisados outros aspectos que podem afetar a opinião da Corte de Contas, como ano eleitoral, resultado financeiro e orçamentário, lei de responsabilidade fiscal, população, PIB, entre outras.

\section{RESULTADOS E DISCUSSÃO}

\section{Descrição e Análise dos Resultados}

No período analisado, de 2012 a 2018, oito conselheiros e três auditores substitutos de conselheiros ficaram responsáveis por relatar os processos de análise de prestações de contas - PCs dos prefeitos. Entre os conselheiros, apenas um de origem do corpo técnico da Corte não tem vida política pregressa. Todos os indicados pela Assembleia Legislativa de SC eram deputados no momento da indicação e tiveram que renunciar ao cargo para assumirem como conselheiros. A vaga de livre nomeação pelo Governador também foi ocupada por dois ex-deputados estaduais - houve troca em 2017 - que interromperam a legislatura em decorrência da nomeação.

Apesar de evidências de que alguns TCs não respeitam a proporção das vagas que deveriam ser ocupadas por membros do MPC e pelos auditores, O TCE/SC manteve a sua composição congruente ao estabelecido no regramento constitucional. Mas isso não significa distanciamento de interferências políticas: em Santa Catarina, o conselheiro de origem do MPC, ocupante, portanto de uma das vagas técnicas, foi vereador da capital por quatro legislaturas consecutivas, exerceu cargos políticos no executivo estadual e a 
família tem de mais de meio século de atuação na política do estado.

Nas 699 PCs analisadas, o alinhamento político entre relator e prefeito foi identificado em 86 delas, ou seja, $12,3 \%$ do total. Como os processos são distribuídos aos relatores por meio de sorteio, esse alinhamento, a princípio, não é intencional. Observa-se que 39\% das prestações de contas foram relatadas por auditores técnicos da Corte, servidores concursados que não possuem vínculo político na investidura ao cargo. Por outro lado, a maior parte dos processos é relatada por Conselheiros indicados politicamente.

Entre os municípios analisados, percebe-se que não há diferença nessa proporção entre conselheiros e auditores no que diz respeito ao tamanho da população. Ou seja, conselheiros não são substituídos em maior ou menor frequência a depender do tamanho do município cujas contas estão sendo apreciadas. No período analisado, inclusive, $57 \%$ das contas da capital do estado foram relatadas por auditores técnicos.

Todavia, isso não representa uma apreciação puramente técnica: o tamanho do município está relacionado ao esforço dos membros do Pleno em modificar a opinião do Relator, ou seja, em apresentar o chamado Voto Divergente - VD. Do total de PCs analisadas, foram identificados 35 votos divergentes. Destes, 17 estão concentrados nos 10 maiores municípios do estado, ou seja, praticamente metade das tentativas de modificar a decisão proferida pelo relator ocorrem nas apreciações dos grandes municípios.

Tabela 1: Proporção de Votos Divergentes.

\begin{tabular}{llll}
\hline Relator & Prestações de Contas & Ocorrência de VD & Porcentagem \\
\hline Conselheiro & 426 & 19 & $4,50 \%$ \\
Auditor Substituto & 273 & 16 & $5,90 \%$ \\
\hline Total & 699 & 35 & $5,00 \%$ \\
\hline
\end{tabular}

Dos relatores contrariados, 19 são conselheiros e 16 auditores substitutos. Proporcionalmente ao volume de processos relatados por cada um, pode-se afirmar que as opiniões emitidas pelos relatores técnicos são 31,4\% mais contrariadas do que as decisões proferidas pelos conselheiros políticos.

Ainda nesse ponto, 77\% dos votos divergentes foram proferidos por conselheiros políticos, em sua maioria para aprovar contas em que a opinião foi pela rejeição. Destes, quase 70\% são projetos de pareceres prévios emitidos por relatores auditores, que foram contrariados. Todos os votos divergentes para reverter uma opinião pela rejeição foram proferidos por conselheiros políticos e nenhum auditor levantou intenção de reverter uma rejeição para uma aprovação. Esse pode ser um indicativo de que a análise realizada por relatores técnicos opinando pela rejeição das contas dos prefeitos chega ao pleno acompanhada da manifestação contrária dos auditores políticos em maior proporção do que a situação inversa.

Por outro lado, manifestações pela rejeição de contas opinadas pela aprovação, na maior parte das vezes, são proferidas auditores técnicos. Inclusive, todos os votos dos auditores técnicos são para esse fim, o que também representa a maioria dos votos nesse sentido $(61,5 \%)$.

Outro ponto importante diz respeito ao alinhamento político: relatores de partidos convergentes aos partidos dos prefeitos foram contrariados somente nos casos em que sugeriram aprovação das contas e todos os votos divergentes, no caso pela rejeição, foram proferidos ou acompanhados por auditores técnicos, sem sucesso na decisão final. Significa dizer que todas as PCs apreciadas por relatores alinhados politicamente ao prefeito, que tiveram suas opiniões contrariadas, venceram por maioria e conseguiram 
aprovar as contas do prefeito alinhado.

Por meio dos votos divergentes, observa-se que, de forma geral, os conselheiros indicados politicamente se pronunciam para tentar aprovar as contas e os conselheiros técnicos para rejeitar. Destacase, ainda, que nenhum relator técnico foi contrariado por outro auditor. Esse é um indicativo de que as análises técnicas são mais consistentes e menos abertas a discussão, quando comparadas às análises dos relatores indicados politicamente.

Os resultados apontam também que os conselheiros políticos têm mais sucesso em seus votos divergentes. Nenhum VD proferido por auditores técnicos foi acatado pelo pleno, ou seja, nenhuma das tentativas de rejeitar contas previamente opinadas pela aprovação prosperaram na decisão final do Pleno. Diferentemente, 91\% das manifestações a fim de reverter um parecer opinando pela rejeição, todas proferidas por relatores políticos, foram acatadas.

Também faz parte do processo de análise das prestações de contas dos prefeitos o voto proferido pelos Procuradores do Ministério Público de Contas (MPC). Presente em todos os processos que tramitam no TCE/SC, o MPC é responsável por defender os interesses da sociedade e fiscalizar o uso do dinheiro público nos municípios catarinenses e no Estado. Entre os processos analisados, a distribuição da opinião do MPC entre aprovação e rejeição é apresentada na tabela 2.

Tabela 2: Voto do MPC e concordância entre Auditores e Conselheiros.

\begin{tabular}{lll|llllll}
\hline & Voto MPC & & \multicolumn{2}{l}{ Voto Conselheiro } & \multicolumn{2}{l}{ Voto Auditor } & \multicolumn{2}{l}{ Total } \\
& Frequência & $\%$ & Concorda & $\%$ & Concorda & $\%$ & Concorda & $\%$ \\
\hline Aprovação & 496 & $71,00 \%$ & 301 & $60,70 \%$ & 191 & $38,50 \%$ & 492 & $99,20 \%$ \\
Rejeição & 203 & $29,00 \%$ & 41 & $20,20 \%$ & 54 & $26,60 \%$ & 95 & $46,80 \%$ \\
\hline Total & 699 & $100,00 \%$ & 342 & $48,90 \%$ & 245 & $35,10 \%$ & 587 & $84,00 \%$ \\
\hline
\end{tabular}

De forma geral, os relatores sorteados, tanto conselheiros quanto auditores acompanham com mais frequência a opinião do MPC quando esta é proferida pela aprovação das contas - 99\% das recomendações nesse sentido foram acatadas, ao passo que menos da metade das opiniões pela rejeição foram seguidas.

Das recomendações pela aprovação, apenas quatro foram contrariadas (por relatores técnicos recomendando rejeição) mas todas foram vencidas pelos votos divergentes dos conselheiros.

Proporcionalmente, considerando o volume de processos analisados por cada relator, os auditores concordam mais com o MPC do que os conselheiros, vide Tabela 3.

Tabela 3: Opinião do MPC em relação ao total de PCs.

\begin{tabular}{llll}
\hline Relator & Prestações de Contas & Concordam com MPC & Porcentagem \\
\hline Conselheiro & 426 & 342 & $80 \%$ \\
Auditor & 273 & 245 & $90 \%$ \\
\hline Total & 699 & 587 & $84 \%$ \\
\hline
\end{tabular}

Das apreciações realizadas por auditores, 90\% seguem a opinião do MPC, o que representa $12,5 \%$ a mais do que o comportamento dos conselheiros. Um quinto das apreciações realizadas por conselheiros chegam a conclusões opostas às análises do Ministério Público de Contas. Isso é refletido também na opinião final do TCE/SC, encaminhada à Câmara de Vereadores, tabela 4. 
Tabela 4: Opinião do MPC e Decisão Final.

\begin{tabular}{lllll}
\hline & Voto MPC & & \multicolumn{2}{c}{ Decisão Final TCE } \\
& Frequência & Porcentagem & Frequência & Porcentagem \\
\hline Aprovação & 496 & $71,00 \%$ & 634 & $90,70 \%$ \\
Rejeição & 203 & $29,00 \%$ & 65 & $9,30 \%$ \\
\hline Total & 699 & $100,00 \%$ & 699 & $100,00 \%$ \\
\hline
\end{tabular}

Observa-se que, enquanto o MPC opinou pela aprovação em 71\% das análises das contas, o TCE/SC emitiu parecer prévio para aprovação de mais de $90 \%$. Consequentemente, os pareceres prévios pela rejeição das contas foram em número menor do que o recomendado pelo MPC. Menos de um terço dos pareceres rejeitados pelo MPC foram rejeitados pelo pleno do TCE em decisão final.

Essa dissonância de opiniões pode ser explicada pelo grau de tolerância de cada apreciador frente às restrições apresentadas. É visível, na amostra analisada, que o MPC é mais sensível às irregularidades que os auditores. Estes, por sua vez, são mais rigorosos que os conselheiros em suas análises, especialmente quando a opinião é pela rejeição.

Em relação às irregularidades que podem ensejar a rejeição de contas, essa pesquisa se concentrou nas principais, apontadas em quadro resumo no Relatório de Auditoria elaborado pela área técnica do TCE/SC para subsidiar a apreciação pelo MPC, Relatores e Pleno, quadro 1.

Quadro 1: Aspectos observados nas PCs.

\begin{tabular}{|l|l|}
\hline Aspecto & Descrição \\
\hline $\begin{array}{l}\text { Conformidade do Balanço } \\
\text { Anual }\end{array}$ & $\begin{array}{l}\text { Balanço anual representando adequadamente situação orçamentária e financeira do Município em } \\
31 \text { de dezembro do exercício analisado. }\end{array}$ \\
\hline $\begin{array}{l}\text { Resultado Financeiro e e } \\
\text { Orçamentário }\end{array}$ & Resultado financeiro e orçamentário deficitário ou superavitário. \\
\hline Cumprimento dos Limites & Cumprimento dos limites da saúde, educação e de gastos com pessoal. \\
\hline Lei da Transparência & Cumprimento da Lei da Transparência. \\
\hline $\begin{array}{l}\text { Lei de Responsabilidade } \\
\text { Fiscal }\end{array}$ & Cumprimento do art. 42 da LRF no último ano de mandato. \\
\hline
\end{tabular}

De forma geral, os municípios apresentam Balanços Anuais que demonstram adequadamente a situação financeira e orçamentária, ou que apresentam inconsistências contábeis que não afetam de forma significativa a posição financeira, orçamentária e patrimonial do exercício em análise. Apenas $10 \%$ das PCs de municípios apresentam divergências relevantes. A relatoria de $60 \%$ destas foi realizada por conselheiros e $40 \%$ por relatores auditores substitutos. A tabela 5 demonstra a frequência de opinião pela rejeição por cada relatoria.

Tabela 5: Rejeição por inadequação do Balanço Anual por Relator.

\begin{tabular}{lllll} 
& \multicolumn{2}{l}{ Balanço Anual inadequado } & \multicolumn{2}{l}{ Opinião pela Rejeição } \\
& Frequência & \% & Frequência & \% \\
\hline Relator Auditor & 27 & $39 \%$ & 17 & $63 \%$ \\
Relator Conselheiro & 42 & $61 \%$ & 13 & $31 \%$ \\
\hline Total & 69 & $100 \%$ & 30 & $43 \%$ \\
\hline
\end{tabular}

Observa-se, que entre os processos que apresentaram Balanço Anual insatisfatório, quando apreciados por relatores auditores, $63 \%$ foram recomendados pela rejeição. Isso é mais que o dobro de recomendações da mesma natureza, comparadas à quando relatadas por conselheiros. Sem deixar de considerar os outros aspectos que fazem parte da análise para fins de emissão de opinião sobre as contas, 
pode-se inferir que a chance de um município que demonstra de forma inadequada a posição orçamentária, financeira e patrimonial ter suas contas aprovadas é aumentada em $86 \%$ quando o relator é um conselheiro indicado politicamente.

Inclusive, entre as PCs apresentadas com Balanços Anuais inadequados, nove tratam-se de prefeitos alinhados politicamente ao Relator. Dessas, 77\% foram recomendadas pela aprovação. Entre as aprovações de prestações de contas na mesma situação, mas que não são prestadas por prefeitos alinhados politicamente ao relator, a proporção de aprovação é menor: 63\%. Esse pode ser um indicativo de que prefeitos alinhados politicamente aos conselheiros relatores têm maiores chances de terem suas contas aprovadas, mesmo quando os Balanços não demonstram adequadamente a real posição do município, quando comparados aos prefeitos não alinhados.

Em relação ao Resultado Orçamentário e Financeiro, 23\% dos municípios apresentam-se orçamentariamente deficitários. Isso significa que executaram mais despesas do que arrecadaram receitas. Já o déficit financeiro está presente em $27 \%$ das PCs. O resultado simultaneamente deficitário ocorre em 138 prestações de contas, tabela 6.

Tabela 6: Déficit Orçamentário e Financeiro e Ano Eleitoral.

\begin{tabular}{llll|llllll}
\hline Ano & PCs & \multicolumn{2}{l}{ Déficit Orç. e Fin. } & \multicolumn{2}{l}{ Recomendação MPC } & \multicolumn{2}{l}{ Recomendação Relator } & \multicolumn{2}{l}{ Decisão Final } \\
& & Frequência & \% & Rejeição & \% & Rejeição & \% & Rejeição & \% \\
\hline Ano Não Eleitoral & 500 & 75 & $15 \%$ & 47 & $63 \%$ & 21 & $28 \%$ & 12 & $16 \%$ \\
Ano Eleitoral & 199 & 63 & $32 \%$ & 53 & $84 \%$ & 40 & $63 \%$ & 30 & $48 \%$ \\
\hline Total & 699 & 138 & $47 \%$ & 100 & $72 \%$ & 61 & $44 \%$ & 42 & $30 \%$ \\
\hline
\end{tabular}

Dessas, quase metade ocorreram em anos eleitorais. Nesses anos, as PCs enquadradas nessa situação têm três vezes mais chances de serem rejeitadas na decisão final, quando comparadas aos anos não eleitorais. Outro critério verificado pelo TCE/SC é o cumprimento do artigo 42 da Lei de Responsabilidade Fiscal (LRF). Gestores que incorrem despesas nos últimos dois quadrimestres de seus mandatos, sem disponibilidade de caixa para cobri-las, estão sujeitos a um tipo de restrição que pode fundamentar a emissão de parecer prévio recomendando a rejeição das contas. Ao todo, 109 prefeitos descumpriram o art. 42 da LRF.

Os votos dos relatores, em sua maioria, foram acompanhados pelo Pleno. Das 58 opiniões pela rejeição, 31 partiram de relatores técnicos enquanto 27 advieram dos conselheiros políticos. Desse total, 12 recomendações tiveram voto divergente proferido, sendo 8 contrários a opinião dos relatores auditores - o que reforça a constatação de que os relatores técnicos têm suas decisões mais contrariadas. Pela análise dessa restrição, constata-se ainda que os relatores auditores toleram menos o descumprimento do dispositivo da LRF quando comparados aos relatores conselheiros, tabela 7.

Tabela 7: Rejeição por descumprimento do art. 42 por Relator.

\begin{tabular}{|c|c|c|c|c|}
\hline & \multicolumn{2}{|c|}{ Descumprimento do art. 42} & \multicolumn{2}{|c|}{ Opinião pela Rejeição } \\
\hline & Frequência & Porcentagem & Frequência & Porcentagem \\
\hline Relator Auditor & 41 & $38 \%$ & 31 & $76 \%$ \\
\hline Relator Conselheiro & 68 & $62 \%$ & 27 & $40 \%$ \\
\hline Total & 109 & $100 \%$ & 58 & $53 \%$ \\
\hline
\end{tabular}


Dos 41 processos analisados por relatores auditores, 76\% são encaminhados para a rejeição. Em contrapartida, os relatores conselheiros se demonstram mais condescendentes com a restrição: apenas 40\% desses casos, quando relatados por conselheiros políticos, são recomendados pela rejeição. Sob o aspecto do alinhamento político, a relação é ainda mais nítida: dos 68 casos de descumprimento do art. 42 relatados por conselheiros, 14 são referentes a prestações de contas de prefeitos cujo partido político é alinhado ao do relator conselheiro, ou seja, $20 \%$ do total. Em todas elas, sem exceção, apesar da irregularidade presente, o relator conselheiro se manifestou pela aprovação das contas. Na sequência, o Pleno também se manifestou favorável à aprovação.

Isso significa dizer que $100 \%$ dos prefeitos que descumpriram o art. 42 - irregularidade gravíssima -, mas que tiveram suas contas relatadas por conselheiros alinhados politicamente, foram aprovados. Acerca do cumprimento dos limites constitucionais e legais, o comportamento dos relatores seguiu a tabela 8.

Tabela 8: Descumprimento de Limites e Opinião pela Rejeição por Relator.

\begin{tabular}{lllll}
\hline & Descumprimento de Limites & \multicolumn{2}{l}{ Opinião pela Rejeição } \\
& Frequência & $\%$ & Frequência & $\%$ \\
\hline Relator Auditor & 66 & $43 \%$ & 35 & $53 \%$ \\
Relator Conselheiro & 86 & $57 \%$ & 22 & $26 \%$ \\
\hline Total & 152 & $100 \%$ & 57 & $38 \%$ \\
\hline
\end{tabular}

Pela tabela acima é possível verificar que os auditores rejeitam as PCs analisadas que apresentam descumprimento de limites em $53 \%$ dos casos, índice que representa mais que o dobro das rejeições emitidas pelos relatores conselheiros.

Isso pode ser um indicativo de que relatores técnicos são menos flexíveis que relatores políticos quando da análise do cumprimento dos limites estabelecidos em normas constitucionais e legais. Por esse raciocínio, os relatores conselheiros estariam, então, mais propensos a afastarem o regramento legal de suas análises. Por fim, conforme apresentado na tabela 9, a análise realizada pelo corpo técnico do TCE/SC aponta que, em média, 70\% dos municípios catarinenses descumprem os dispositivos da Lei da Transparência, tabela 9.

Tabela 9: Cumprimento dos dispositivos da Lei Complementar no 131/2009.

\begin{tabular}{lll} 
& Lei da Transparência & \\
& Frequência & Porcentagem \\
\hline Cumprimento & 188 & $30 \%$ \\
Descumprimento & 439 & $70 \%$ \\
Não se aplica* & 72 & $0 \%$ \\
\hline Total & 699 & $100 \%$ \\
\hline
\end{tabular}

* PCs relativas a 2012 de municípios menores de 50 mil habitantes. Cumprimento passou a ser obrigatório a partir de 2013.

Essa restrição é, de todas as análises, a que menos interfere na opinião dos relatores. 0 fato de descumprir a Transparência não significa muito quando se fala em rejeição das contas: das 439 PCs que descumpriram o dispositivo, apenas 55 tiveram a recomendação pela rejeição, ou seja, $12,5 \%$. A verificação do cumprimento ou não desse dispositivo, pelos resultados apresentados, é mera formalidade dentro do Tribunal de Contas do Estado de Santa Catarina. 


\section{CONCLUSÕES}

O estudo traz evidências empíricas de que existe influência de interesses políticos na apreciação das contas de governos municipais no estado de Santa Catarina e, metodologicamente, atingiu os objetivos. Apontou-se que relatores auditores são mais contrariados que relatores conselheiros indicados politicamente e, na maioria das vezes, trata-se de conselheiros tentando reverter uma opinião técnica pela rejeição. Relatores auditores só se manifestam de forma divergente para rejeitar contas em que a opinião do conselheiro foi pela aprovação. Além disso, auditores substitutos de conselheiros não divergem de opinião entre si, isto é, são mais consistentes. Os resultados demonstram que, de forma geral, os conselheiros políticos se empenham mais pela aprovação das contas e os conselheiros técnicos mais pela rejeição. Isso pode ser um indício de que conselheiros políticos tendem a proteger mais os chefes do executivo e a serem menos rígidos em suas análises. $\mathrm{O}$ fato de auditores técnicos não divergirem entre si também reforça a possibilidade de existência de interferência política nas análises realizadas pelos conselheiros indicados.

Sob outros aspectos, também ficou evidenciada a diferença de comportamento entre os conselheiros: proporcionalmente, considerando o volume de processos analisados por cada relator, os auditores concordam mais com o MPC do que os conselheiros; é visível, na amostra analisada, que o MPC é mais sensível às irregularidades que os auditores; estes, por sua vez, são mais rigorosos que os conselheiros em suas análises, especialmente quando a opinião é pela rejeição.

Da análise dos balanços anuais, pode-se inferir que a chance de um município que demonstra de forma inadequada a posição orçamentária, financeira e patrimonial ter suas contas aprovadas é aumentada em $86 \%$ quando o relator é um conselheiro indicado politicamente. Outro dado que chama atenção é que 100\% dos prefeitos que descumpriram o art. 42 - irregularidade gravíssima -, mas que tiveram suas contas relatadas por conselheiros alinhados politicamente, foram aprovados. Acerca dos limites estabelecidos em normas constitucionais e legais, os relatores conselheiros se mostram mais propensos a afastarem o regramento legal de suas análises.

O cerne geral desses resultados está na diferença de comportamento entre os relatores, já que o único aspecto que os diferencia é a forma de investidura no cargo - política por indicação, ou técnica por concurso. Se todos os conselheiros levassem em consideração apenas critérios técnicos em suas análises, não haveria mais ou menos flexibilização diante das irregularidades apontadas. Dessa forma, esses resultados sugerem que a natureza política do conselheiro influencia na apreciação das contas dos governos municipais catarinenses.

Como limitações, destaca-se que a pesquisa são contemplou todos os municípios do estado, apenas o correspondente a $83,21 \%$ da população. Outro ponto que merece atenção está no fato de que o partido do prefeito, para efeito de análise da convergência político-partidária, foi determinado pelo partido momento da eleição, sem considerar possíveis trocas ao longo da gestão.

Considerando a similaridade do formato de composição dos tribunais de contas pelo país e os fortes indícios de politização, é possível que as conclusões aqui apresentadas possam servir de referencial para 
pesquisas similares. Por fim, cabe assinalar que o Controle Externo tem o papel importante e necessário de zelar pelo interesse da coletividade. Quando outros interesses são observados em detrimento do interesse público, a sociedade deixa de ser representada e ocorre desvio de finalidade. Os resultados contribuem para reforçar a discussão acerca da forma com que o Controle Externo é exercido no Brasil e a independência dos conselheiros nos processos de prestação de contas.

\section{REFERÊNCIAS}

ABRAHAM, M.. Curso de direito financeiro brasileiro. Elsevier Brasil, 2013.

ALMEIDA-SANTOS, P. S.; BOHN, R. M.; HONGYU, K.; MATIASPEREIRA, J.. Probabilidade de sucesso ou fracasso na prestação de contas públicas: uma análise logística com dados painel. RIGC, v.16, p.1-19, 2018.

AMORIM, V. A. J.. O julgamento de contas de gestão prestadas por prefeito municipal. Revista Eletrônica Universo Tributário, 2012

ATALIBA, G.. República e constituição. São Paulo: Revista dos Tribunais, 1985.

BRASIL. Constituição da República Federativa do Brasil. Brasília: DOU, 1988.

BRASIL. Lei Complementar n. 101 de $\mathbf{4}$ de maio de 2000. Estabelece normas de finanças públicas voltadas para a responsabilidade na gestão fiscal e dá outras providências. Brasília: DOU, 2000.

BRASIL. Lei Complementar n. 135 de $\mathbf{4}$ de junho de 2010. Altera a Lei Complementar no 64, de 18 de maio de 1990, que estabelece, de acordo com o $\S 90$ do art. 14 da Constituição Federal, casos de inelegibilidade, prazos de cessação e determina outras providências, para incluir hipóteses de inelegibilidade que visam a proteger a probidade administrativa e a moralidade no exercício do mandato. Brasília: DOU, 2010.

BRASIL. Proposta de Emenda à Constituição no 2, de 2018. Altera os arts. 73 e 84 da Constituição Federal para modificar a forma de composição do Tribunal de Contas da União, dos Tribunais de Contas dos Estados e do Distrito Federal e dos Tribunais e Conselhos de Contas dos Municípios. Brasília: DOU, 2018.

BRASIL. Proposta de Emenda à Constituição no 329, de 2013. Altera a forma de composição dos Tribunais de Contas; submete os membros do Ministério Público de Contas ao Conselho Nacional do Ministério Público - CNMP e os Conselheiros e Ministros dos Tribunais de Contas ao Conselho Nacional de Justiça - CNJ e dá outras providências. Brasília: DOU, 2013.

BRASIL. Súmula 653 do Supremo Tribunal Federal. Brasília: DOU, 2003.

BRITTO, C. A.. O regime constitucional dos Tribunais de Contas. Revista Diálogo Jurídico, n.9, p.13-31, 2001.

CANOTILHO, J. J. G.. Direito constitucional. 5 ed. Coimbra: Livraria Almedina, 1991.
CAPOBIANCO, J. M.. Composição e atribuições dos Tribunais de Contas no Brasil. 2012.

CASTRO, R. P. A.. Sistema de controle interno: uma perspectiva do modelo de gestão pública gerencial. Belo Horizonte: Fórum, 2007.

DEPRÁ, V. O. B.; LEAL, M. C. H.. Fiscalização do orçamento público: accoutability e controle social da atividade financeira do Estado. Revista do Direito Público, v.12, n.3, p.216-241, 2017.

ENTERRÍA, E. G.. La Constitución y el Tribunal Constitucional. Madri: Civitas, 1985.

HELLER, G.; SOUZA, G. C.. Função de controle externo e função administrativa: separação e colaboração na Constituição de 1988. Revista de Direito Administrativo, v.278, n.2, p.71-96, 2019.

MARTINS, L.; LIBONATI, J.; MIRANDA, L.; FREITAS, M. Controle Externo das Contas Públicas: A Influência Política no Julgamento das Contas dos Prefeitos do Estado de Pernambuco. Sociedade, Contabilidade e Gestão, v.15, n.2, p.162-176, 2020

MEDAUAR, O.. Controle da administração pública pelo Tribunal de Contas. BDA: Boletim de Direito Administrativo, v.8, n.2, p.83-99, 1992.

MEIRELLES, H. L.. A administração pública e seus controles. Revista de Direito Administrativo, v.114, p.23-33, 1973.

OLIVEIRA, J. M.. Quem fiscaliza os Tribunais de Contas?. Entrevista concedida à Pública, 2018.

ROCHA, C. A. A.. O modelo de controle externo exercido pelos tribunais de contas e as proposições legislativas sobre o tema. Brasília: Senado Federal, 2002.

SANTA CATARINA. Lei Complementar n. 202, de 15 de dezembro de 2000. Institui a Lei Orgânica do Tribunal de Contas do Estado de Santa Catarina e adota outras providências. Florianópolis: DOE, 2000.

SANTA CATARINA. Resolução TC n. TC-06/2001, de 11 de setembro de 2002. Aprova o Regimento Interno do Tribunal de Contas do Estado de Santa Catarina. Tribunal de Contas do Estado de Santa Catarina. Florianópolis: DOE, 2002.

SIRAQUE, V.. O controle social da função administrativa do Estado: possibilidades e limites na Constituição de 1988. Dissertação (Mestrado) - Universidade de São Paulo, São Paulo, 2004.

A CBPC - Companhia Brasileira de Produção Científica (CNPJ: 11.221.422/0001-03) detém os direitos materiais desta publicação. Os direitos referem-se à publicação do trabalho em qualquer parte do mundo, incluindo os direitos às renovações, expansões e disseminações da contribuição, bem como outros direitos subsidiários. Todos os trabalhos publicados eletronicamente poderão posteriormente ser publicados em coletâneas impressas sob coordenação da Sustenere Publishing, da Companhia Brasileira de Produção Científica e seus parceiros autorizados. Os (as) autores (as) preservam os direitos autorais, mas não têm permissão para a publicação da contribuição em outro meio, impresso ou digital, em português ou em tradução. 